\title{
GLOSSARY
}

\section{Advanced glossary on genetic epidemiology}

\section{N Malats, F Calafell}

This is the last of a series of glossaries on terms used in genetic epidemiology published by the journal. This glossary covers the most advanced genetic terms, most of which are related to new study designs and laboratory techniques. It provides the reader with examples and references of real studies that applied each of the study designs defined in the glossary. This should help the reader grasp the subtleties of each of these strategies and will allow the reader to research the literature according to their interest.

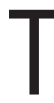
he previous glossaries on basic molecular and genetic concepts $^{12}$ gave the basis for the understanding of those included here.

Given the space constraints, we chose not to be exhaustive and be concise. Hence, we again encourage the interested reader to "explore" the classic bibliography on genetics and genetic epidemiology. ${ }^{3-6}$

\section{AFFECTED SIB-PAIR APPROACH}

Study design used to find genetic factors contributing to a complex trait. It tests for linkage by considering the proportion of shared alleles between affected sib-pairs at markers spaced over the whole genome or over a section of it. A null distribution of the expected relative frequencies of sibs sharing zero, one or two alleles at a marker can be derived and tested against the observed data. An excess of allele sharing at a marker may indicate the presence in its vicinity of a gene contributing to the disease. This method also permits testing of gene-environment interaction. This design was applied by Lachmeijer et al to assess the involvement of ILlB and ILIRN gene polymorphisms in causing pre-eclampsia. ${ }^{7}$ They collected 150 pairs of sisters that had suffered pre-eclampsia while pregnant and typed two polymorphisms at ILlB and one at ILIRN. Unfortunately, the degree of allele sharing among sisters did not suggest that those genes were involved in pre-eclampsia.

\section{ALLELE SPECIFIC AMPLIFICATION}

Polymerase chain reaction based methods for detecting disease causing mutations that consist in amplifying specifically one or both alleles by using specific primers in one or two independent reactions. If two allele specific primers are used in a single reaction, additional chemistry is needed to determine which primer produced the amplification.
Correspondence to: Dr N Malats, Carrer del Dr Aiguader 80, E-08003 Barcelona, Spain nuria@imim.es

See end of article for authors' affiliation

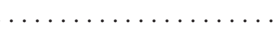

individuals. The alleles analysed may be thought to contribute to the disease or be in linkage disequilibrium with any such causative variation. It can provide sufficient power to distinguish slight variations in disease risks being more sensitive than linkage methods when the genes of interest contribute to disease susceptibility but are neither necessary nor sufficient to cause disease. The methodology it uses is the same as used by epidemiological studies (cohort and case-control design). For instance, Perikac-Vance et al had mapped a gene conferring susceptibility to late onset Alzheimer's disease at chromosome $19 \mathrm{q} 13.2^{8}$; as apoliprotein E is found bound to the amyloid plaques characteristic of Alzheimer's disease and is also found in that genome region, it became a candidate gene for Alzheimer's disease. This was confirmed by Strittmatter et al by typing variants of the ApoE gene in 30 affected individuals and in 91 presumably healthy controls. ${ }^{9}$ They found that the frequency of the APOE- $\epsilon 4$ allele was significantly higher in the patients than in the controls, which showed that this allele confers susceptibility to Alzheimer's disease.

\section{CASE ONLY DESIGN}

Approach to screen gene-environment interactions under the assumption of independence between exposure and genotype in the population. This design does not require control subjects. Therefore, sample sizes will be less than half than those required in case-control studies and the estimated odds ratios will not suffer from potential biases related to control selection. Cases are distributed in a $2 \times 2$ table according to their genetic and environmental exposure status. To further explore the differences between a case only and a case-control design we suggest the reader looks at the study by Bai et al that compared both approaches to assess geneenvironmental interaction on the disease liability. ${ }^{10}$

\section{CASE-PARENTAL CONTROL DESIGN}

Design based on the TDT test, which compares the relative frequencies of transmitted and nontransmitted alleles from parents to their affected offspring. It prevents the confounding effects of population stratification and permits testing of gene-environmental interactions by stratifying cases according to their environmental exposure status. For example, in a seminal paper, Spielman et al compared the genotypes at the insulin gene of juvenile diabetics and their parents and found that heterozygous parents transmitted to their affected children class 1 more often that other classes of alleles, and therefore concluded that susceptibility to juvenile diabetes is linked to the insulin gene. ${ }^{11}$

\section{ASSOCIATION ANALYSIS}

Comparison of the frequency of alleles in candidate genes between unrelated affected and unaffected 


\section{GENE MAPPING}

Any strategy that permits finding the chromosomal location of one or more genes, often related to a disease. See affected sib-pair approach, case-parental control design, and linkage analysis.

\section{HERITABILITY}

Fraction of the total phenotypic variation in a population that is caused by genetic differences between individuals: genetic variance/total variance. The genetic variance is the part of the total variance that is caused by allelic variations at whatever loci influence the trait. The total variance is the amount of variation in phenotype in a defined population. It only applies to a population on which observations are made and cannot be extended to other populations that have different allele frequencies or environments. Therefore, it cannot be used to explain differences between populations. Lichtenstein et al applied this strategy to assess the effects of heritable and environmental factors in cancers at various sites on the basis of the twin registries from Finland, Sweden, and Denmark. ${ }^{12}$

\section{LINKAGE ANALYSIS}

Strategy for gene mapping by testing for linkage between markers and phenotypes using families. In classic linkage analysis the transmission model is fixed (possibly with parameter values obtained from segregation analysis) and the likelihoods (LOD scores) of the disease and marker data are compared under the null hypothesis of no linkage and the alternative hypothesis of linkage. Non-parametric linkage analysis avoids fixing an explicit mode of inheritance of the disease. Free application programs for human genetic linkage analysis are listed, classified, and available for downloading (http://linkage. rockefeller.edu/). For instance, using data from 39 families containing individuals affected with cystic fibrosis, Tsui et al found that the inheritance of alleles at the D0CRI-917 polymorphism seemed to be linked to cystic fibrosis. ${ }^{13}$ Later on, and guided by this discovery, Kerem et al found that cystic fibrosis was caused by mutations in the CFTR gene, which is close to the D0CRI-917 polymorphism. ${ }^{14}$

\section{LINKAGE DISEQUILIBRIUM}

A condition in which alleles at two loci or genes are found together in a population at a greater frequency than that predicted simply by the product of their individual allele frequencies. Alleles at markers near disease causing genes tend to be in linkage disequilibrium in the affected individuals. This is particularly the case in isolated, homogeneous populations, in which it can be assumed that most affected individuals carry the same mutation. Thus, Hastbacka et al found that diastrophic dysplasia, a rare disease almost confined to Finland, mapped to the genome region 5q32-q33.1 by observing that, in patients, alleles at the polymorphims in that region were in close linkage disequilibrium with each other. $^{15}$

\section{LOD SCORE}

A statistical estimate, obtained in linkage analysis, which indicates whether alleles at two loci are inherited together more often than expected and are thus likely to be placed near each other on a chromosome. A LOD score is the ratio of two probabilities: (1) the probability of the observed inheritance of a trait (usually a disease) and alleles at a marker in a pedigree if they were linked given a inheritance model for the trait and a recombination probability between marker and disease, and (2) the probability of the observed inheritance of a trait and marker in a pedigree under the assumption that they are not linked. A LOD score is the logarithm of the ratio of those two probabilities. LOD scores can be added across pedigrees, and are usually taken to indicate significant linkage if they are above three. The recombination fraction that gives the highest LOD score from a marker of known genomic location can be used to map a gene.

\section{MICROARRAY}

A novel method of studying large numbers of genes simultaneously by automating and miniaturising a hybridisation detection system. The method uses a robot to precisely apply tiny droplets containing DNA to glass slides. Researchers then attach fluorescent labels to DNA from the cell they are studying. The labelled probes are allowed to bind to complementary DNA strands on the slides. The slides are put into a scanning microscope that can measure the brightness of each fluorescent dot; brightness reveals how much of a specific DNA fragment is present.

\section{MULTIFACTORIAL THRESHOLD (MFT) MODELS OF INHERITANCE}

Models that assume the joint effect of multiple genes and environmental exposures in determining the liability of an individual to present the trait of interest. A threshold is assumed under which the subject would not present the trait and above it would.

\section{POLYMERASE CHAIN REACTION (PCR)}

A procedure for obtaining a large number of copies of a particular segment of DNA. The principle depends on the requirement by DNA polymerase of a primer with a 3' end to which nucleotides can be added. Two such synthetic primers define a segment that is replicated in a thermal cycle of denaturation, reannealing (reformation of complementary primerDNA structure), and replication. Each cycle, which takes two to three minutes, doubles the amount of DNA between the primer boundaries. Thirty cycles would yield $2^{30}$ copies. PCR has made it possible to characterise extremely small amounts of DNA.

\section{RESTRICTION FRAGMENT LENGTH POLYMORPHISM (RFLP)}

Genetic variation at the site where a restriction enzyme cuts a piece of DNA. Such variations affect the ability of the restriction enzyme to cut, and therefore, produce different fragment sizes. Most RFLPs are single base pair changes in the 4-6 bp target sequence of the restriction enzyme. Vice versa, many single nucleotide polymorphisms (SNPs) are RFLPs and can be detected with this technique.

\section{SEGREGATION ANALYSIS}

Analysis of the inheritance ratios of offspring from a particular parental cross to test for conformity with Mendelian theory. Either genotypes or phenotypes can be the object of segregation analysis.

\section{SEQUENCING}

Determining the exact order of the base pairs in a segment of DNA by biochemical methods. Semiautomated biochemical methods are available for sequencing, which are based in the sequential incorporation of fluorescently labelled nucleotides.

\section{SINGLE STRAND CONFORMATION POLYMORPHISM (SSCP)}

Fast and simple technique widely used for mutation detection in various diseases. Basically, a fragment of interest is amplified by $P C R$, followed by electrophoresis in nondenaturing gel. The mutant DNA is separated from the normal due to the difference in mobility in electrophoresis, which is believed to be caused by the conformational change of the 
single stranded mutant DNA. Usually the DNA fragment size is restricted to less than $200 \mathrm{bp}$ as the sensitivity of PCR-SSCP decreases with fragment size.

\section{WHOLE GENOME SCAN}

Linkage analysis in which markers placed at regular intervals and covering the whole genome are typed. It is often the first approach when no genetic information is available about a particular phenotype. For instance, Stefansson et al found that neuregulin-1 is a candidate gene for schizophrenia after typing 950 microsatellite markers covering the whole genome in 110 Icelandic patients for whom they had reconstructed their genealogical relationships. ${ }^{16}$

\section{Contributors}

Both authors have contributed equally to the manuscript.

\section{Authors' affiliations}

N Malats, Institut Municipal d'Investigació Mèdica, Barcelona, Spain F Calafell, Departament de Ciències Experimentals i de la Salut, Universitat Pompeu Fabra, Barcelona, Spain

\section{REFERENCES}

1 Calafell F, Malats N. Basic molecular genetics for epidemiologists. J Epidemiol Community Health 2003;57:398-400

2 Malats N, Calafell F. Basic glossary on genetic epidemiology. J Epidemiol Community Health 2003;57:480-2.

3 Various authors. Genetic epidemiology. Epidemiol Rev 1997;19. (Monographic issue on genetic epidemiology).
4 Hartwell LL, Hood L, Goldberg ML, et al. Genetics, from genes to genomes. Boston: McGraw Hill, 2000.

5 King RC, Stansfield WD. A dictionary of genetics. Oxford: Oxford University Press, 1997.

6 Strachan T, Read AP. Human molecular genetics. Oxford: Bios Publishers, 2001.

7 Lachmeijer AM, Nosti-Escanilla MP, Bastiaans EB, et al. Linkage and association studies of ILIB and ILIRN gene polymorphisms in preeclampsia. Hypertens Pregnancy 2002;21:23-38.

8 Pericak-Vance MA, Bebout JL, Gaskell PC Jr, et al. Linkage studies in familial Alzheimer disease: evidence for chromosome 19 linkage. Am J Hum Genet 1991;48:1034-50.

9 Strittmatter WJ, Weisgraber KH, Huang DY, et al. Binding of human apolipoprotein $E$ to synthetic amyloid beta peptide: isoform-specific effects and implications for late-onset Alzheimer disease. Proc Natl Acad Sci USA 1993:90:8098-102.

10 Bai Y, Goldin LR, Goldstein AM. Gene x environment interaction from case-control and case-case approaches. Genet Epidemiol 2001;21:S825-30.

11 Spielman RS, McGinnis RE, Ewens WJ. Transmission test for linkage disequilibrium: the insulin gene region and insulin-dependent diabetes mellitus (IDDM). Am J Hum Genet. 1993;52:506-16.

12 Lichtenstein P, Holm NV, Verkasalo PK, et al. Environmental and heritable factors in the causation of cancer-analyses of cohorts of twins from Sweden, Denmark, and Finland. N Engl J Med 2000;343:78-85.

13 Tsui LC, Buchwald M, Barker D, et al. Cystic fibrosis locus defined by a genetically linked polymorphic DNA marker. Science 1985;230:10547 .

14 Kerem B, Rommens JM, Buchanan JA, et al. Identification of the cystic fibrosis gene: genetic analysis. Science 1989;245: 1073-80.

15 Hastbacka J, de la Chapelle A, Kaitila I, et al. Linkage disequilibrium mapping in isolated founder populations: diastrophic dysplasia in Finland. Nat Genet 1992;2:204-11.

16 Stefansson H, Sigurdsson E, Steinthorsdottir V, et al. Neuregulin 1 and susceptibility to schizophrenia. Am J Hum Genet 2002;71:877-92.

\section{SPEAKER'S CORNER}

\section{The right to health of the European Union citizens. A strategy for a social European construction}

$\mathrm{T}$ The fundamentals of the European construction were only economic until the Unique Act was passed. Then some social aspects were partially incorporated.

Several advances in the field of common citizens' rights have, indeed, been introduced (free movement and residency, etc). Advances in matters such as education, health care, culture, and the fight against illicit drugs have been quite limited.

In the field of health policies, only a few measures of health protection to prevent diseases by means of research, improvement of information, and health education, etc, have been adopted to date. In summary, the social counterparts of the economic measures are not very concrete.

The absence of a common social policy may create serious problems and imbalances in public health, as a consequence of the influence of the health care expenditure on every country's economic competence ability. Differences in the services offered may attract patients toward the countries with best public services. The free circulation of persons may endanger the persistence of health services as ours, because we are receptors of retired people, whose health care consumption is fourfold that of the younger. Differences in the technological means available, and in professional training, may lead to an attraction of the best professionals by the most developed countries.

A common and homogeneous social policy should be imple- mented. Nevertheless, many of the reforms developed by the different countries were aimed to reduce the public expenditure, to introduce the market in to health care relations, and to increase the presence of the private sector in it. The results of such a strategy are being catastrophic for the rationality, the efficiency, and the equity of the health care systems, and also for their users' right to health.

Some proposals should, therefore, be advanced to get a Letter of the Rights to Health of the Europeans that ought to be incorporated to the project now debated. It should include the right to health protection for all. A common public health system is needed for that. It must contemplate universal health care provisions, and a homogenous offer in different countries. A public insurance, and a redistributive financing, ensuring a minimal common health care expenditure, must guarantee the equity in access to services. The present existing differences between health systems should not be forgotten. We should be conscious that we live in a progressively more interconnected world. If we wish a really consistent EU, the persons' rights ought to play an increasingly prominent part.

M Garcia, M Sanchez Bayle, Secretario y Portavoz respectivamente de la Federación de Asociaciones para la Defensa de la Sanidad Publica, Madrid, Spain Correspondence to: DrM Sanchez Bayle; fadspu@teleline.es 